Published in final edited form as:

Curr Opin Pediatr. 2019 February ; 31(1): 21-27. doi:10.1097/MOP.0000000000000717.

\title{
Management of Pediatric Low-Grade Glioma
}

\author{
Peter de Blank, Pratiti Bandopadhayay, Daphne Haas-Kogan, Maryam Fouladi, Jason \\ Fangusaro \\ University of Cincinnati and Cincinnati Children's Hospital Medical Center (PdB, MF), 3333 \\ Burnet Avenue, Cincinnati, OH 45229. Dana-Farber/Boston Children's Cancer and Blood \\ Disorder Center; Department of Pediatrics, Harvard Medical School; Broad Institute of MIT and \\ Harvard (PB, DHK) 25 Shattuck Street, Boston, MA 02115.Children's Healthcare of Atlanta and \\ Emory University School of Medicine, Atlanta GA (JF), 1405 Clifton Rd, Atlanta, GA 30322
}

\begin{abstract}
Purpose of review: Pediatric low-grade gliomas have been treated with similar therapies for the last 30 years. Recent biological insights have allowed a new generation of targeted therapies to be developed for these diverse tumors. At the same time, technological advances may redefine the late toxicities associated with radiation therapy. Understanding recent developments in pediatric low-grade glioma therapy is essential to the management of these common pediatric tumors.
\end{abstract}

Recent findings: It is now well understood that aberrations of the MAPK pathway are key to oncogenesis in low-grade gliomas. This understanding, along with the development of available targeted agents, have heralded a new era of understanding and treatment for these patients. Promising, sustained responses are now being seen in early phase trials among patients with multiply recurrent/progressive disease. Also, newer and highly conformal radiation approaches such as proton beam radiotherapy maintain efficacy of radiation but limit radiation-associated toxicities.

Summary: Novel therapies offer the potential for tumor control with greatly reduced toxicities. However, late effects of these therapies are just now being explored. Improved radiation approaches and targeted agents have the potential to redefine traditional therapy for pediatric lowgrade glioma.

\section{Keywords}

pediatric low-grade glioma; BRAF; targeted therapy; radiation therapy

\section{Introduction}

Recent technical and scientific advances offer novel therapies to children with inoperable or progressive pediatric low-grade glioma (pLGG). Newer radiation techniques, such as proton beam radiation, offer the potential to limit radiation doses delivered to healthy tissue in order

Corresponding Author: Peter de Blank, MD, MSCE, 3333 Burnet Avenue, MLC 7018, Cincinnati, OH 45229-3026, Phone: 513-517-2068, Fax: 513-636-3549, peter.deblank@cchmc.org.

Conflicts of Interest 
to reduce radiation-associated morbidities. Advances in our understanding of the biology of low-grade gliomas have similarly identified the critical role of activation of the mitogenactivated protein (MAP) kinase pathway, paving the way for clinical trials targeting this pathway with promising early results. These advances have expanded our therapeutic options for pLGG and may herald a new era in their treatment.

\section{Epidemiology}

Low-grade gliomas are the most common central nervous system (CNS) tumor among children, accounting for approximately one-third of pediatric brain tumors. $(1,2)$ These tumors include a heterogeneous group of histologies classified by the World Health Organization (WHO) as grades I or II.(3) Prognosis for these tumors is generally excellent, with 10-year overall survival (OS) between 85-96\%.(4-6) However, survivors of pediatric glioma often suffer functional, neurologic and endocrine complications from their disease or treatment.(7) As a result, current treatment regimens are designed to maintain this excellent overall survival while reducing late effects.

\section{Treatment for pLGG}

The mainstay of therapy for progressive or symptomatic pLGG is complete surgical resection whenever feasible. Completely resected tumors often require no further therapy, and even subtotal resection may induce tumor quiescence for prolonged periods.(8) However, pLGG that cannot be resected or progress after resection often require additional therapy.

Historically, radiation therapy has been used in the up-front and salvage settings for the treatment of pLGG, with a phase II study of 54 Gy delivered to the tumor with a $10 \mathrm{~mm}$ margin resulting in 5-year progression-free survival (PFS) and OS of $87 \%$ and $96 \%$, respectively.(9) However, traditional photon radiotherapy is associated with troubling side effects including cognitive decline, endocrine deficiencies, secondary malignancies, vascular damage and growth abnormalities. (9-11) Thus, radiotherapy is generally reserved for a subset of pLGG patients who are older and for whom less toxic treatments such as surgery, chemotherapy and targeted agents, have been exhausted.

In the 1980s, chemotherapy was introduced for young children with progressive or incompletely resected pLGG as a means to delay or obviate the need for radiation therapy. This is especially important in children with neurofibromatosis type-1 (NF-1) who are at increased risk of pLGG, typically within the optic pathway. They are also at an increased risk of developing a secondary malignancy due to their germline mutation. Chemotherapy regimens in newly-diagnosed pLGG achieve 3-year PFS between 50-80\% depending on the regimen (see Table 1). The most commonly used chemotherapy regimens for pLGGs are carboplatin and vincristine, a combination of thioguanine, procarbazine, CCNU and vincristine (TPCV) or vinblastine alone. Although carboplatin and vincristine may offer slightly inferior PFS compared to TPCV (not statistically significant)(12), the combination avoids the risks of secondary malignancy and infertility posed by the TPCV regimen. 


\section{Recent Advances in Radiation Therapy}

Sophisticated radiotherapy techniques have been used to harness the efficacy of radiation therapy while mitigating its toxicities. Progress in imaging technology, including highresolution computed tomography and magnetic resonance imaging and improvements in patient immobilization have allowed tumor targeting with smaller margins and more conformal radiation plans. In addition to sophisticated conformal radiation approaches, newer radiation modalities have allowed sparing of normal brain regions. Proton beam radiotherapy is such a modality that limits the volume of normal brain that is exposed to low and intermediate doses of radiation compared to photon radiotherapy. In a retrospective series of 32 patients treated with proton beam radiotherapy for low-grade glioma with a median follow-up time of 7.6 years, 8-year PFS and OS were $82.8 \%$ and $100 \%$, respectively. (13) Although generally well tolerated, significant decline in neurocognitive outcomes were seen in young children (less than 7 years old) and patients whose left temporal lobe/ hippocampus received significant doses. Higher doses to the hypothalamus or pituitary were associated with endocrinopathies, and two cases of moya moya disease were documented as well.

Another highly conformal radiation approach, stereotactic radiation, has been studied in a prospective trial at Dana-Farber Cancer Institute. Relatively small (less than $5 \mathrm{~cm}$ ) tumors were treated upfront or as salvage with a mean radiation dose of $52.2 \mathrm{~Gy}$ in $1.8 \mathrm{~Gy}$ fractions. At five years, PFS and OS were $82.5 \%$ and $97.8 \%$, respectively, and no marginal failures were observed. The authors concluded that stereotactic radiotherapy provides excellent local control for children with small, localized pLGG. Also, limiting the treatment margins helps limit radiation-related toxicities without compromising local control.(14)

Taken together, highly conformal radiation approaches appear to be safe and effective methods to achieve local control but are still best reserved for the salvage setting. There does not appear to be clear benefit in the immediate post-operative setting. When radiation therapy is employed for pLGG, doses of 52-54 Gy are effective, and planning set-up margin can safely be limited to $1 \mathrm{~cm}$ or less to protect adjacent normal tissues.

\section{The Genomic Landscape of pLGG}

The last decade has generated unparalleled insights into the underlying biology of pLGG. Long recognized to exhibit clinical heterogeneity, recent landmark genomic profiling efforts(15-17), have confirmed pLGGs to be distinct from low-grade gliomas that occur in adults, and to collectively represent a group characterized by distinct driver alterations. pLGGs most frequently have somatic driver genetic alterations that result in activation of the MAPK pathway.(15-18) Similar MAPK activation can be seen as a result of syndromes genetically predisposed to pLGG, including NF1(19) and tuberous sclerosis.(20) MAPK activation resulting in downstream activation of the mtor pathway is predominant in pLGG and offers a useful target for therapy. $(21,22)$ The majority of tumors exhibit only a single identifiable driver alteration. As a result, pLGGs are most commonly defined by single structural variants or rearrangements that result in the expression of a fusion protein. 
Rearrangements afflicting the genes $B R A F$ and $K I A A 1549$ are the most frequent somatic driver alterations across all pLGGs, and are enriched within pilocytic astrocytomas.(15-17, 23, 24) KIAA1549-BRAF rearrangements result in expression of a fusion protein consisting of the N'-terminal of the KIAA1549 protein and the truncated C'-terminal of BRAF, which contains the BRAF kinase. The N' terminal negative regulatory domain of BRAF is not retained in the KIAA1549-BRAF fusion, which results in constitutive activation of the BRAF kinase with downstream activation of MAPK signaling. BRAFrearrangements involving other fusion partners including RNF13O(16), CLCN6(16), GNAI1(16), GIT2(25), FXR1(15) and MKRN1(16) have also been observed less frequently. A smaller cohort of pLGGs harbor activating $B R A F V 600 E$ mutations $(15,16,18)$ and are enriched in gangliogliomas $(15,17)$ and pleomorphic xanthoastrocytomas $(26)$, frequently associated with loss of $C D K N 2 A(27)$.

The expanding number of pLGGs subjected to genomic profiling has allowed further association of recurrent driver alterations with specific pLGG subtypes. Diffuse astrocytomas have been shown to be enriched with $B R A F$ mutations or rearrangements involving the $M Y B$ (and the related $M Y B L 1$ ) family of transcription factors $(15,17,28,29)$. These $M Y B$ rearrangements result in C' terminal truncation of $M Y B / M Y B L 1$, with resultant loss of its negative regulatory domain and aberrant expression of the truncated protein product. $M Y B-Q K I$ fusion proteins have been shown to define angiocentric gliomas(17), which have also recently been reported to present as brainstem tumors(30, 31). $M Y B$ rearrangements involving other fusion partners including PCDHGA1 and MAML2 have also been described $(15,17,32)$; however, their clinical associations remain to be defined. FGFR 1 mutations and rearrangements involving FGFR 1 (including duplications of the FGFR 1 kinase) occur more commonly in dysembryoplastic neuro-epithelial tumors(16, 32,33 ), which can also be associated with germline $F G F R 1$ alterations(33). While pilocytic astrocytomas are largely defined by BRAF alterations, a subset harbor FGFR1 and NTRK2 rearrangements(16). Finally, while IDH1 mutations are much more commonly associated with adult low-grade gliomas, they are also infrequently observed in young children(34). The clinical significance and natural history of pediatric IDH1 mutant low-grade gliomas remains to be defined.

\section{Targeted Treatments for Pediatric LGG}

Numerous agents that target the MAPK pathway, such as MEK or BRAF inhibitors (see Figure 1) are currently being tested in pLGGs. The drug that has been studied most extensively to date is selumetinib (AZD6244), a selective and potent orally-available, nonATP competitive small-molecule inhibitor of MEK-1/2. Promising preclinical data(35), led to the phase I Pediatric Brain Tumor Consortium (PBTC) trial of selumetinib in children with recurrent and refractory pLGG (NCT01089101). The recommended phase 2 dose (RP2D) determined among 38 eligible children was $25 \mathrm{mg} / \mathrm{m}^{2} /$ dose twice daily (36). Five of 25 patients treated at the RP2D had a centrally-reviewed partial response (PR) and 37\% completed all 26 cycles of protocol therapy with at least stable disease. The dose limiting toxicities (DLT) included rash, increased amylase/lipase and mucositis(36). 
These results led to the ongoing PBTC phase II trial (NCT01089101) evaluating selumetinib in recurrent/refractory pLGG among 6 strata. The stratification was based upon tumor histology, location, NF1 status, and specific BRAF aberration. Preliminary data revealed response rates of $36-40 \%$ in children with NF1 associated pLGG as well as non-NF1 pilocytic astrocytomas harboring a BRAF aberration(37). The most commonly reported toxicities were grade 1/2 CPK elevation, diarrhea, hypoalbuminemia, elevated AST and rash. The Children's Oncology Group (COG) is planning two phase 3 upfront randomized clinical trials comparing selumetinib to standard chemotherapy (carboplatin and vincristine) among patients with NF1- and non-NF1 associated pLGG (personal communication, COG CNS Committee, 2018).

Trametinib is another oral MEK-1/2 inhibitor already approved by the FDA for the treatment of BRAF-mutant melanoma(38). A phase 1/2 pediatric trial (NCT02124772) enrolled 23 patients with refractory/recurrent pLGG. PRs were observed in 3 patients by local investigators and confirmed in 1 patient by independent review (39). The most common adverse events were diarrhea, rash and paronychia.

Binimetinib (MEK-162), a small molecule allosteric inhibitor of MEK-1/2(40) has completed phase 1 testing trial (NCT02285439) in children with recurrent, refractory or progressive pLGG and other Ras/Raf pathway activated malignancies. Seventeen children with pLGG were enrolled and treated at doses between 16 to $32 \mathrm{mg} / \mathrm{m}^{2} /$ dose twice daily. An MTD was not established. Four pLGG patients achieved a PR, and 12/17 completed at least 36 weeks of therapy with a median decrease of $29 \%$ in 2-dimensional tumor measurements(41). The most common toxicities were asymptomatic elevated CPK, rash, dry skin and lymphopenia. A phase II study is currently ongoing.

Cobemitinib, another oral MEK inhibitor, is FDA-approved in combination with vemurafinib for the treatment of unresectable or metastatic BRAFV600- mutated melanoma and is also undergoing phase 1 testing in recurrent pediatric solid tumors (NCT02639546).

Direct targeting of BRAF using vemurafinib or dabrafenib is another promising approach being studied in pLGG. Dabrafenib and vemurafenib are both orally-bioavailable, potent and selective inhibitors of BRAF kinases that harbor V600 mutations, binding to the ATPbinding domain of mutant BRAF. Both dabrafenib and vemurafenib are FDA-approved in

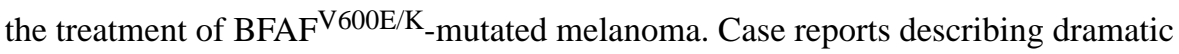
responses to dabrafenib in infants and children with recurrent $L G G$ that harbor BRAFV600E mutations $(42,43)$ led to an ongoing multi-institutional phase I/IIa trial (NCT01677741) of dabrafenib in children with recurrent $\mathrm{BRAF}^{\mathrm{V} 600}$ mutated solid tumors. Thirty-two children with pLGG have been enrolled. The RP2D was $4.5 \mathrm{mg} / \mathrm{kg} / \mathrm{day}$ for children $>12$ years and $5.25 \mathrm{mg} / \mathrm{kg} /$ day for children $\unlhd 2$ years. Independent central radiologic review revealed 13 PR and 1 complete resection (CR)(44) for an overall RR of 44\%, with a 1-year PFS and OS of $74 \%$ and $44 \%$, respectively. (45). The disease-specific phase 2 component of the study is ongoing. Similarly, early reports of promising vemurafenib activity in children with recurrent $\mathrm{BRAF}^{\mathrm{V} 600 \mathrm{E}}$ mutant $\mathrm{pLGG}$ treated $(46,47)$ led to the ongoing Pacific NeuroOncology Consortium (PNOC) phase I trial of vemurafenib in children with recurrent or refractory gliomas containing the $\mathrm{BRAF}^{\mathrm{V} 600 \mathrm{E}}$ mutation (NCT01748149). 
MAPK-targeting combination therapies are also being explored. Kondyli et al reported that among 6 patients with refractory V600E-mutated pLGG treated with a combination of trametinib and dabrafenib, 4 patients experienced PR, $1 \mathrm{SD}$ and 1 progressive disease (PD) (48). A phase 2 industry-sponsored trial evaluating this combination is currently underway in children with both high and low-grade glioma with $\mathrm{BRAF}^{\mathrm{V} 600}$ mutations

(NCT02684058).

Therapies targeting the mtor pathway, such as everolimus, are also currently being evaluated. An ongoing PNOC phase 2 study evaluates everolimus in children with recurrent/ progressive pLGG (NCT01734512).

Unfortunately, as with most novel agents, there is a learning curve to our understanding. BRAF and MEK inhibitors harbor unique toxicity profiles that include rashes, cardiac dysfunction, ocular toxicity, CPK elevation and skin infections $(36,49)$. Prevention and management of these side effects have improved over time and with practitioners' experience. In addition, we now understand the importance of tailoring therapy for pLGGs based on a thorough understanding of the distinct mechanisms of action specific to different BRAF alterations. A pediatric phase II trial of sorafenib, a multi-kinase inhibitor (targeting BRAF, VEGFR, PDGFR, and c-kit) in children with recurrent LGG was halted because of unexpected progression in 9 of 11 patients., including 3 with KIAA1549-BRAF fusion and NF1. Studies have confirmed that this effect is a result of paradoxical ERK activation(50) also reported in NF1loss. Thus, first-generation BRAF inhibitors such as vemurafenib and dabrafenib which target the monomeric forms of BRAF should not be used for tumors with BRAF fusion which function as dimers. This is an important consideration since pilocytic astrocytomas, the most common pLGG, commonly harbor the KIAA1549-BRAF fusion. Fortuitously, second-generation BRAF inhibitors such as TAK580, bypass this paradoxical activation and can target both monomeric and dimeric forms of the BRAF oncoprotein, (51). A phase I/II study of TAK580 in children with recurrent/refractory gliomas is currently underway by PNOC.

\section{Conclusion}

Early results of novel radiation techniques and MAPK-targeting strategies in pLGG have been quite promising. Novel agents targeting BRAF aberrations have demonstrated high response rates, good PFS and overall manageable toxicity in patients with recurrent disease.

However, numerous questions regarding these targeted therapies remain unanswered, such as the appropriate duration of therapy, durability of response once therapy has ceased, late toxicities with chronic administration and the use of these agents as up-front therapy or in combination with other agents. Carefully developed prospective clinical trials will better answer these and other important questions.

\section{Acknowledgements:}

PdB is supported by a grant from the St. Baldrick's Foundation (St. Baldrick's Scholar Grant). PB is supported by grants from St. Baldrick's Foundation and A Kids Brain Tumor Cure, PLGA Foundation supported by grants from St. Baldrick's Foundation and A Kids Brain Tumor Cure, PLGA Foundation, as well as 
Novartis for an unrelated project. DH-K is supported by the William M. Wood Foundation and NINDS 1R01NS091620. MF is supported by Cure Starts Now, DIPG Collaborative, Curing Kids cancer, PLGA Foundation.

PB was receives support from Novartis for an unrelated project.

\section{References:}

1. Farwell JR, Dohrmann GJ, Flannery JT. Central nervous system tumors in children. Cancer. 1977;40(6):3123-32. [PubMed: 201364]

2. A study of childhood brain tumors based on surgical biopsies from ten North American institutions: sample description. Childhood Brain Tumor Consortium. Journal of neuro-oncology. 1988;6(1):923. [PubMed: 3294353]

3. WHO Classification of Tumours of the Central Nervous System. Revised fourth edition ed Geneva, Switzerland: WHO Press; 2016408 p.

4. Ostrom QT, de Blank PM, Kruchko C, Petersen CM, Liao P, Finlay JL, et al. Alex's Lemonade Stand Foundation Infant and Childhood Primary Brain and Central Nervous System Tumors Diagnosed in the United States in 2007-2011. Neuro-oncology. 2015;16 Suppl 10:x1-x36. [PubMed: 25542864]

5. Bandopadhayay P, Bergthold G, London WB, Goumnerova LC, Morales La Madrid A, Marcus KJ, et al. Long-term outcome of 4,040 children diagnosed with pediatric low-grade gliomas: an analysis of the Surveillance Epidemiology and End Results (SEER) database. Pediatric blood \& cancer. 2014;61(7):1173-9. [PubMed: 24482038]

6. Krishnatry R, Zhukova N, Guerreiro Stucklin AS, Pole JD, Mistry M, Fried I, et al. Clinical and treatment factors determining long-term outcomes for adult survivors of childhood low-grade glioma: A population-based study. Cancer. 2016;122(8):1261-9. [PubMed: 26970559]

7. Armstrong GT, Liu Q, Yasui Y, Huang S, Ness KK, Leisenring W, et al. Long-term outcomes among adult survivors of childhood central nervous system malignancies in the Childhood Cancer Survivor Study. Journal of the National Cancer Institute. 2009;101(13):946-58. [PubMed: 19535780]

8. Shaw EG, Wisoff JH. Prospective clinical trials of intracranial low-grade glioma in adults and children. Neuro-oncology. 2003;5(3):153-60. [PubMed: 12816721]

9. Merchant TE, Conklin HM, Wu S, Lustig RH, Xiong X. Late effects of conformal radiation therapy for pediatric patients with low-grade glioma: prospective evaluation of cognitive, endocrine, and hearing deficits. Journal of clinical oncology : official journal of the American Society of Clinical Oncology. 2009;27(22):3691-7. [PubMed: 19581535]

10. Ullrich NJ, Robertson R, Kinnamon DD, Scott RM, Kieran MW, Turner CD, et al. Moyamoya following cranial irradiation for primary brain tumors in children. Neurology. 2007;68(12):932-8. [PubMed: 17372129]

11. Pierce SM, Barnes PD, Loeffler JS, McGinn C, Tarbell NJ. Definitive radiation therapy in the management of symptomatic patients with optic glioma. Survival and long-term effects. Cancer. 1990;65(1):45-52. [PubMed: 2104571]

12. Ater JL, Zhou T, Holmes E, Mazewski CM, Booth TN, Freyer DR, et al. Randomized study of two chemotherapy regimens for treatment of low-grade glioma in young children: a report from the Children's Oncology Group. Journal of clinical oncology : official journal of the American Society of Clinical Oncology. 2012;30(21):2641-7. [PubMed: 22665535]

13. Greenberger BA, Pulsifer MB, Ebb DH, MacDonald SM, Jones RM, Butler WE, et al. Clinical outcomes and late endocrine, neurocognitive, and visual profiles of proton radiation for pediatric low-grade gliomas. International journal of radiation oncology, biology, physics. 2014;89(5):10608.

14. Marcus KJ, Goumnerova L, Billett AL, Lavally B, Scott RM, Bishop K, et al. Stereotactic radiotherapy for localized low-grade gliomas in children: final results of a prospective trial. International journal of radiation oncology, biology, physics. 2005;61(2):374-9.

15. Zhang J, Wu G, Miller CP, Tatevossian RG, Dalton JD, Tang B, et al. Whole-genome sequencing identifies genetic alterations in pediatric low-grade gliomas. Nat Genet. 2013;45(6):602-12. [PubMed: 23583981] ** (Ater) - This study provided the pLGG community one of the largest 
prospective chemotherapy trials for pLGG and serves as a benchmark of success and response rates for most ongoing and future comparative trials.

16. Jones DT, Hutter B, Jager N, Korshunov A, Kool M, Warnatz HJ, et al. Recurrent somatic alterations of FGFR1 and NTRK2 in pilocytic astrocytoma. Nat Genet. 2013;45(8):927-32. [PubMed: 23817572]

17. Bandopadhayay P, Ramkissoon LA, Jain P, Bergthold G, Wala J, Zeid R, et al. MYB-QKI rearrangements in angiocentric glioma drive tumorigenicity through a tripartite mechanism. Nat Genet. 2016;48(3):273-82. [PubMed: 26829751]

18. MacConaill LE, Campbell CD, Kehoe SM, Bass AJ, Hatton C, Niu L, et al. Profiling critical cancer gene mutations in clinical tumor samples. PloS one. 2009;4(11):e7887.

19. Khatua S, Gutmann DH, Packer RJ. Neurofibromatosis type 1 and optic pathway glioma: Molecular interplay and therapeutic insights. Pediatric blood \& cancer. 2018;65(3).

20. Bongaarts A, Giannikou K, Reinten RJ, Anink JJ, Mills JD, Jansen FE, et al. Subependymal giant cell astrocytomas in Tuberous Sclerosis Complex have consistent TSC1/TSC2 biallelic inactivation, and no BRAF mutations. Oncotarget. 2017;8(56):95516-29. [PubMed: 29221145]

21. Pachow D, Wick W, Gutmann DH, Mawrin C. The mTOR signaling pathway as a treatment target for intracranial neoplasms. Neuro-oncology. 2015;17(2):189-99. [PubMed: 25165193]

22. Banerjee S, Crouse NR, Emnett RJ, Gianino SM, Gutmann DH. Neurofibromatosis-1 regulates mTOR-mediated astrocyte growth and glioma formation in a TSC/Rheb-independent manner. Proc Natl Acad Sci U S A. 2011;108(38):15996-6001. [PubMed: 21896734]

23. Sievert AJ, Jackson EM, Gai X, Hakonarson H, Judkins AR, Resnick AC, et al. Duplication of $7 q 34$ in pediatric low-grade astrocytomas detected by high-density single-nucleotide polymorphism-based genotype arrays results in a novel BRAF fusion gene. Brain Pathol. 2009;19(3):449-58. [PubMed: 19016743] ** (Jones) - This trial was among a handful of early basic and translational work that helped define the BRAF KIAA1549 fusion as a hallmark of most classic pilocytic astrocytomas, the most common pLGG.

24. Jones DT, Kocialkowski S, Liu L, Pearson DM, Backlund LM, Ichimura K, et al. Tandem duplication producing a novel oncogenic BRAF fusion gene defines the majority of pilocytic astrocytomas. Cancer Res. 2008;68(21):8673-7. [PubMed: 18974108]

25. Helgager J, Lidov HG, Mahadevan NR, Kieran MW, Ligon KL, Alexandrescu S. A novel GIT2BRAF fusion in pilocytic astrocytoma. Diagn Pathol. 2017;12(1):82. [PubMed: 29141672]

26. Dias-Santagata D, Lam Q, Vernovsky K, Vena N, Lennerz JK, Borger DR, et al. BRAF V600E mutations are common in pleomorphic xanthoastrocytoma: diagnostic and therapeutic implications. PloS one. 2011;6(3):e17948.

27. Phillips JJ, Gong H, Chen K, Joseph NM, van Ziffle J, Bastian BC, et al. The genetic landscape of anaplastic pleomorphic xanthoastrocytoma. Brain Pathol. 2018.

28. Ramkissoon LA, Horowitz PM, Craig JM, Ramkissoon SH, Rich BE, Schumacher SE, et al. Genomic analysis of diffuse pediatric low-grade gliomas identifies recurrent oncogenic truncating rearrangements in the transcription factor MYBL1. Proc Natl Acad Sci U S A. 2013;110(20): 8188-93. [PubMed: 23633565]

29. Gonda TJ, Buckmaster C, Ramsay RG. Activation of c-myb by carboxy-terminal truncation: relationship to transformation of murine haemopoietic cells in vitro. EMBO J. 1989;8(6):1777-83. [PubMed: 2670562]

30. D’Aronco L, Rouleau C, Gayden T, Crevier L, Decarie JC, Perreault S, et al. Brainstem angiocentric gliomas with MYB-QKI rearrangements. Acta Neuropathol. 2017;134(4):667-9. [PubMed: 28803398]

31. Chan E, Bollen AW, Sirohi D, Van Ziffle J, Grenert JP, Kline CN, et al. Angiocentric glioma with MYB-QKI fusion located in the brainstem, rather than cerebral cortex. Acta Neuropathol. 2017;134(4):671-3. [PubMed: 28776091]

32. Qaddoumi I, Orisme W, Wen J, Santiago T, Gupta K, Dalton JD, et al. Genetic alterations in uncommon low-grade neuroepithelial tumors: BRAF, FGFR1, and MYB mutations occur at high frequency and align with morphology. Acta Neuropathol. 2016;131(6):833-45. [PubMed: 26810070] 
33. Rivera B, Gayden T, Carrot-Zhang J, Nadaf J, Boshari T, Faury D, et al. Germline and somatic FGFR1 abnormalities in dysembryoplastic neuroepithelial tumors. Acta Neuropathol. 2016;131(6): 847-63. [PubMed: 26920151]

34. Ferris SP, Goode B, Joseph NM, Kline CN, Samuel D, Gupta N, et al. IDH1 mutation can be present in diffuse astrocytomas and giant cell glioblastomas of young children under 10 years of age. Acta Neuropathol. 2016;132(1):153-5. [PubMed: 27161253]

35. Kolb EA, Gorlick R, Houghton PJ, Morton CL, Neale G, Keir ST, et al. Initial testing (stage 1) of AZD6244 (ARRY-142886) by the Pediatric Preclinical Testing Program. Pediatr Blood Cancer. 2010;55(4):668-77. [PubMed: 20806365] ** (Banerjee) - This Phase I trial was one of the first published MAPK targeted therapies in pLGG not only establishing the RP2D but also showing tolerability and responses.

36. Banerjee A, Jakacki RI, Onar-Thomas A, Wu S, Nicolaides T, Young Poussaint T, et al. A phase I trial of the MEK inhibitor selumetinib (AZD6244) in pediatric patients with recurrent or refractory low-grade glioma: a Pediatric Brain Tumor Consortium (PBTC) study. Neuro Oncol. 2017;19(8): 1135-44. [PubMed: 28339824]

37. Fangusaro JO-TA, Young-Poussaint T, Wu S, Ligon AH, Lindeman NI, Banerjee A, Packer R, Kilburn LB, Pollack IF, Jakacki R, Qaddoumi IA, Fisher PG, Dhall G, Baxter PA, Kreissman SG, Doyle LA, Smith MA, Dunkel IJ, Fouladi M. A phase II prospective study of selumetinib in children with recurrent or refractory low-grade glioma (LGG): A Pediatric Brain Tumor Consortium (PBTC) study. J Clin Oncol 35, 2017 (suppl; abstr 10504). 2017;35.

38. Zhao Y, Adjei AA. The clinical development of MEK inhibitors. Nat Rev Clin Oncol. 2014;11(7): 385-400. [PubMed: 24840079]

39. Bouffet E KM, Hargrave D, Roberts S, Aerts I, Broniscer A, Geoerger B, Dasgupta K, Tseng L, Russo M, Mookerjee B, Moertel C. TRAMETINIB THERAPY IN PEDIATRIC PATIENTS WITH LOW-GRADE GLIOMAS (LGG) WITH BRAF GENE FUSION; A DISEASE-SPECIFIC COHORT IN THE FIRST PEDIATRIC TESTING OF TRAMETINIB. Neuro-Oncology, . 2018; Volume 20(Issue suppl_2 ):Pages i114.

40. Woodfield SE, Zhang L, Scorsone KA, Liu Y, Zage PE. Binimetinib inhibits MEK and is effective against neuroblastoma tumor cells with low NF1 expression. BMC Cancer. 2016;16:172. [PubMed: 26925841]

41. Robison N PJ, Malvar J, Gruber-Filbin M, Loret de Mola R, Dorris K, Bendel A, Bowers D, Bornhorst M, Gauvain K, Leary S, Diaz P, Tan YJ , Margol A, Dhall G, Rosser T, Bandopadhayay P, Davidson T, Ullrich N, Borchert M, Nelson M, Sinai C, Ligon K, Sposto R, Kieran M. A PHASE I DOSE ESCALATION TRIAL OF THE MEK1/2 INHIBITOR MEK162 (BINIMETINIB) IN CHILDREN WITH LOW-GRADE GLIOMAS AND OTHER RAS/RAF PATHWAY-ACTIVATED TUMORS. Neuro-Oncology. 2018;20(Issue suppl_2, 22 ):Pages i114.

42. Lassaletta A, Guerreiro Stucklin A, Ramaswamy V, Zapotocky M, McKeown T, Hawkins C, et al. Profound clinical and radiological response to BRAF inhibition in a 2-month-old diencephalic child with hypothalamic/chiasmatic glioma. Pediatr Blood Cancer. 2016;63(11):2038-41. [PubMed: 27398937]

43. Bavle A, Jones J, Lin FY, Malphrus A, Adesina A, Su J. Dramatic clinical and radiographic response to BRAF inhibition in a patient with progressive disseminated optic pathway glioma refractory to MEK inhibition. Pediatr Hematol Oncol. 2017;34(4):254-9. [PubMed: 29040023]

44. Kieran MW, Hargrave DR, Cohen KJ, Aerts I, Dunkel IJ, Hummel TR, et al. Phase 1 study of dabrafenib in pediatric patients (pts) with relapsed or refractory BRAF V600E high- and low-grade gliomas (HGG, LGG), Langerhans cell histiocytosis (LCH), and other solid tumors (OST). 2015;33(15_suppl):10004-.

45. Kieran MW BE, Broniscer A, Cohen KJ, Geoerger B, Hansford JR, Hingorani P, Aerts I, Andre N, Bertozzi-Salamon A, Dunkel IJ, Hummel TR, Leary S, Moreno L, Russo MW, Tseng L, Dasgupta K, Nebot N, Whitlock J, Hargrave DR. Efficacy and safety results from a phase I/IIa study of dabrafenib in pediatric patients with BRAF V600-mutant relapsed refractory low-grade glioma. Abstracts frpm the 2018 Annual ASCO meeting, Chicago, IL J Clin Oncol 2018;36.

46. del Bufalo F, Carai A, Figa-Talamanca L, Pettorini B, Mallucci C, Giangaspero F, et al. Response of recurrent BRAFV600E mutated ganglioglioma to Vemurafenib as single agent. J Transl Med. 2014;12:356. [PubMed: 25524464] 
47. van Tilburg CM, Selt F, Sahm F, Bachli H, Pfister SM, Witt O, et al. Response in a child with a BRAF V600E mutated desmoplastic infantile astrocytoma upon retreatment with vemurafenib. Pediatr Blood Cancer. 2018;65(3).

48. Kondyli M EB, Saint-Martin C, Farmer JP, Crevier L, Perreault S, Jabado N. TRAMETINIB AND DABRAFENIB FOR REFRACTORY/INOPERABLE PEDIATRIC LOW GRADE GLIOMAS. Neuro-Oncology.19(Issue suppl_6):vi185-vi6.

49. Cabanillas ME, Patel A, Danysh BP, Dadu R, Kopetz S, Falchook G. BRAF inhibitors: experience in thyroid cancer and general review of toxicity. Horm Cancer. 2015;6(1):21-36. [PubMed: 25467940]

50. Karajannis MA, Legault G, Fisher MJ, Milla SS, Cohen KJ, Wisoff JH, et al. Phase II study of sorafenib in children with recurrent or progressive low-grade astrocytomas. Neuro-oncology. 2014;16(10):1408-16. [PubMed: 24803676]

51. Zhang C, Spevak W, Zhang Y, Burton EA, Ma Y, Habets G, et al. RAF inhibitors that evade paradoxical MAPK pathway activation. Nature. 2015;526(7574):583-6. [PubMed: 26466569]

52. Aquino VM, Fort DW, Kamen BA. Carboplatin for the treatment of children with newly diagnosed optic chiasm gliomas: a phase II study. Journal of neuro-oncology. 1999;41(3):255-9. [PubMed: 10359145]

53. Kadota RP, Kun LE, Langston JW, Burger PC, Cohen ME, Mahoney DH, et al. Cyclophosphamide for the treatment of progressive low-grade astrocytoma: a Pediatric Oncology Group phase II Study. J Pediatr Hematol Oncol. 1999;21(3):198-202. [PubMed: 10363852]

54. Packer RJ. Treatment of chiasmatic/hypothalamic gliomas of childhood with chemotherapy In: Smith JL, Katz RS, editors. Neuro-ophthalmology enters the nineties. Hialeah: Dutton; 1988 p. 145-51.

55. Ater JL, Xia C, Mazewski CM, Booth TN, Freyer DR, Packer RJ, et al. Nonrandomized comparison of neurofibromatosis type 1 and non-neurofibromatosis type 1 children who received carboplatin and vincristine for progressive low-grade glioma: A report from the Children's Oncology Group. Cancer. 2016;122(12):1928-36. [PubMed: 27061921]

56. Laithier V, Grill J, Le Deley MC, Ruchoux MM, Couanet D, Doz F, et al. Progression-free survival in children with optic pathway tumors: dependence on age and the quality of the response to chemotherapy--results of the first French prospective study for the French Society of Pediatric Oncology. Journal of clinical oncology : official journal of the American Society of Clinical Oncology. 2003;21(24):4572-8. [PubMed: 14673044]

57. Lassaletta A, Scheinemann K, Zelcer SM, Hukin J, Wilson BA, Jabado N, et al. Phase II Weekly Vinblastine for Chemotherapy-Naive Children With Progressive Low-Grade Glioma: A Canadian Pediatric Brain Tumor Consortium Study. Journal of clinical oncology : official journal of the American Society of Clinical Oncology. 2016;34(29):3537-43. [PubMed: 27573663]

58. Massimino M, Spreafico F, Riva D, Biassoni V, Poggi G, Solero C, et al. A lower-dose, lowertoxicity cisplatin-etoposide regimen for childhood progressive low-grade glioma. Journal of neurooncology. 2010;100(1):65-71. [PubMed: 20151174]

59. Gnekow AK, Walker DA, Kandels D, Picton S, Giorgio P, Grill J, et al. A European randomised controlled trial of the addition of etoposide to standard vincristine and carboplatin induction as part of an 18-month treatment programme for childhood ( $</=16$ years) low grade glioma - A final report. Eur J Cancer. 2017;81:206-25. [PubMed: 28649001] 
Key Points:

- $\quad$ Therapies that target the activated Ras/Raf/MEK pathway in pLGG offer a novel mechanism of tumor control with well-tolerated toxicities.

- Questions remain regarding how best to incorporate targeted chemotherapy in the management of pLGG.

- $\quad$ Advanced radiation therapy techniques, such as proton therapy, deliver radiation doses more precisely than prior methods and may offer reduced toxicity for children with pLGG when other treatment options are exhausted. 


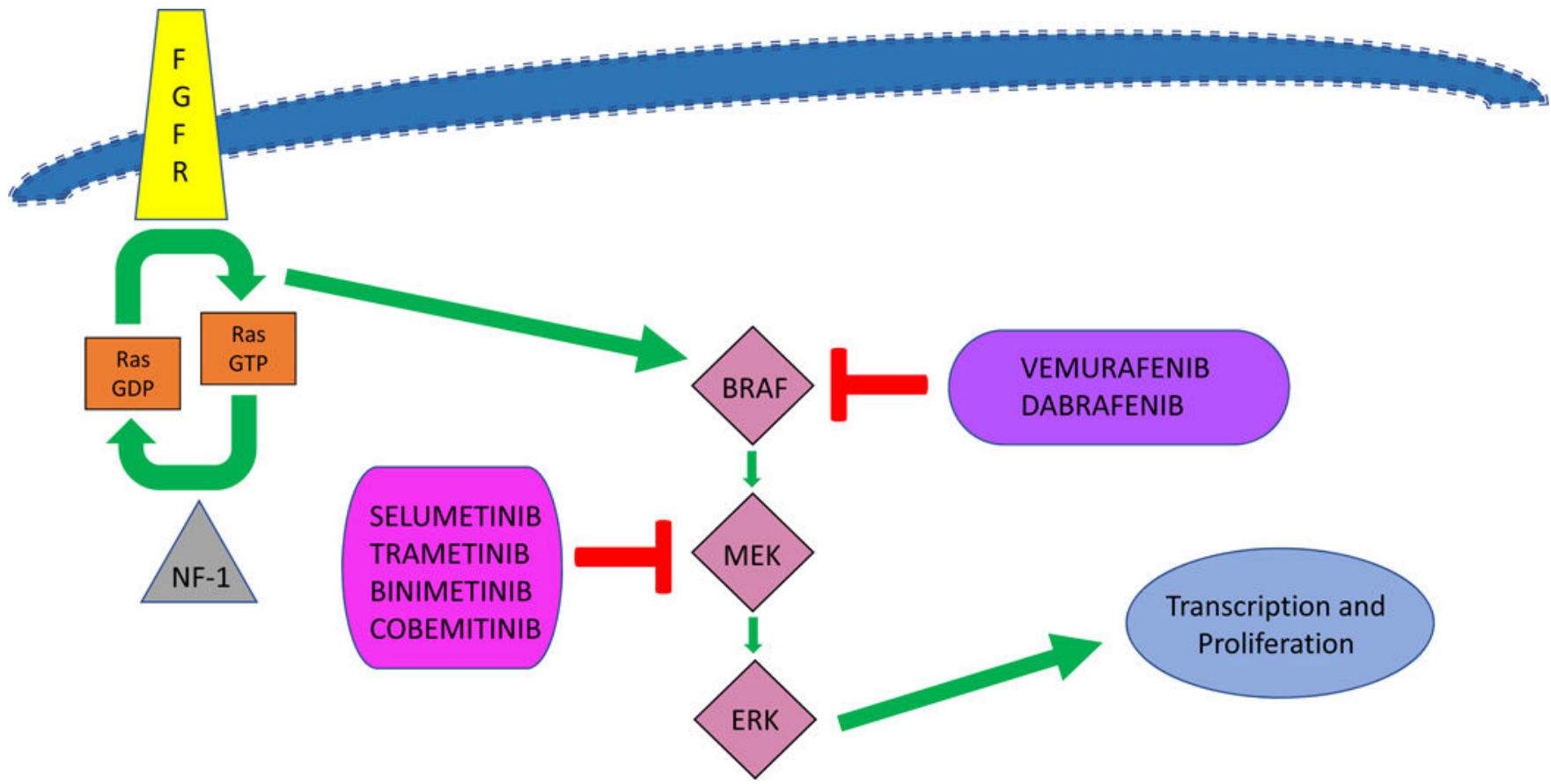

Figure 1 (original):

A simplified diagram of the MAP kinase pathway 


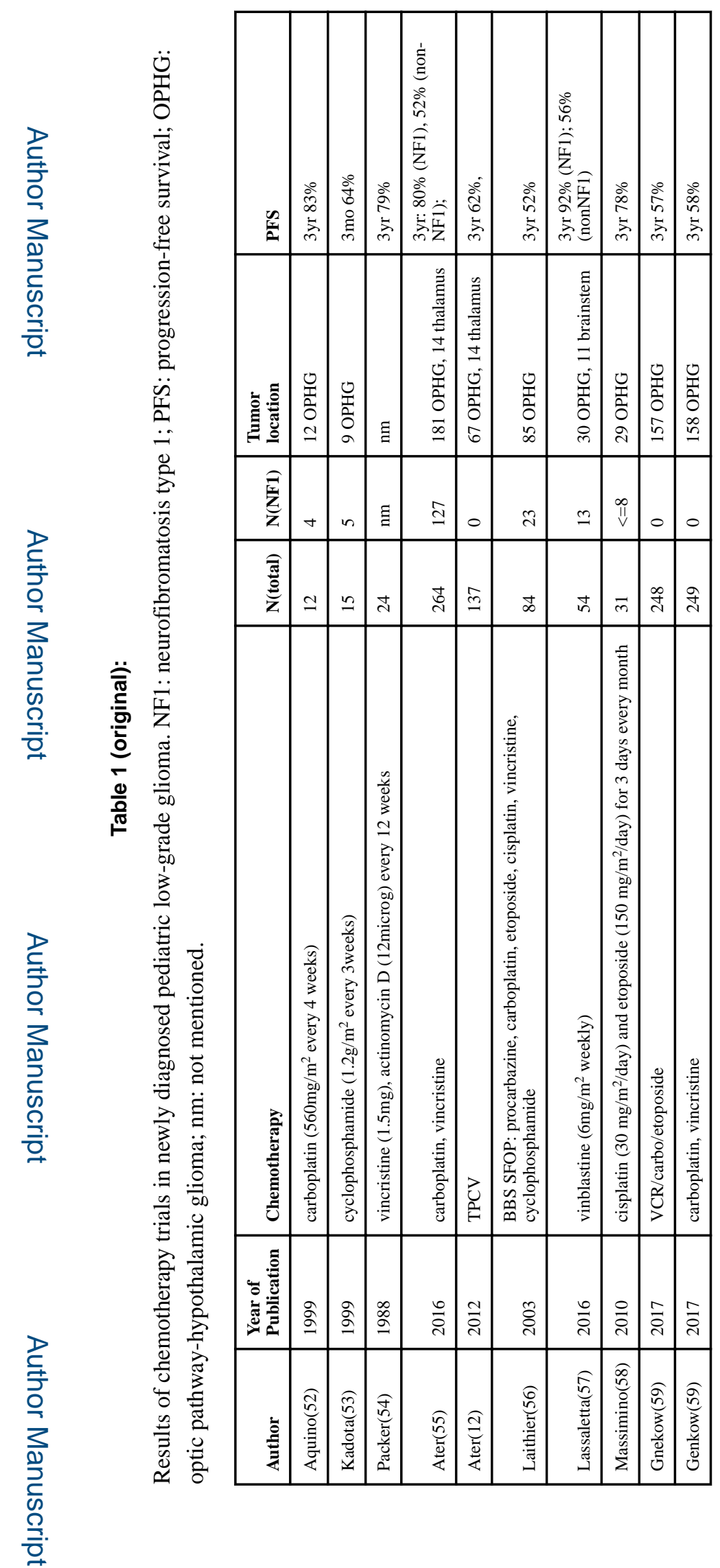

Curr Opin Pediatr: Author manuscript; available in PMC 2019 July 30. 